\title{
Information systems to support sustainable consumption and sustainable supply
}

\author{
Jing Zhang • Luis F. Luna-Reyes • Holly Jarman • \\ Giri Kumar Tayi
}

Published online: 30 November 2014

(c) Springer Science+Business Media New York 2014

\section{Introduction}

Responding to rising concerns about environmental sustainability, governments around the world have committed to the promotion of more sustainable consumption patterns [7]. Mainstream approaches to promoting sustainable consumption often involve government interventions to correct prices, and to provide regulatory frameworks to influence producers to become more eco-efficient [17]. Unfortunately, the success of these actions is frequently limited by information barriers. Consumers have limited information about the social and environmental impacts of products, and have long relied instead on price information as well as information available on the product package in making their buying decisions [15]. This lack of information creates difficulties for consumers

\author{
J. Zhang $(\bowtie)$ \\ Graduate School of Management, Clark University, Worcester, \\ MA 01610-1477, USA \\ e-mail: JIZhang@clarku.edu \\ L. F. Luna-Reyes \\ Business School, Fundacion Universidad de las Americas \\ Puebla, CS 213 F, Santa Catarina Martir, San Andres Cholula, \\ 72810 Puebla, Mexico \\ e-mail: luisf.luna@udlap.mx \\ H. Jarman \\ Department of Health Management and Policy, Center for Law, \\ Ethics and Health, University of Michigan School of Public \\ Health, 1420 Washington Heights, Room M3523, Ann Arbor, \\ MI 48103-2029, USA \\ e-mail: hjarman@umich.edu \\ G. K. Tayi \\ School of Business, SUNY at Albany, Room: BB 317, 1400 \\ Washington Ave, Albany, NY 12222, USA \\ e-mail: gtayi@albany.edu
}

when assessing and understanding the implications of their choices. Similarly, lack of integrated information systems that can capture, process and deliver actionable information about environmental impacts to all members in the sustainable supply chain could potentially disrupt the entire chain. These disruptions could, in turn, create higher costs and risks for all actors in the supply chain.

Despite the connection between sustainable consumption and sustainable supply chain management, current research shows little integration between these areas. Recent technological developments have the potential to streamline the information flow from producer to consumer within supply chains, helping consumers to make more sustainable buying choices. Ontologies, Linked Data, and Semantic Web technologies can handle the problems that arise when integrating massive amounts of multi-thematic and multi-perspective information from heterogeneous sources to answer complex questions that cut through supply chain domain boundaries. The innovative use of information technologies could reduce the "information asymmetry" that pervades modern supply chains. Reducing barriers to information would benefit not only consumers but also other actors in the supply chain.

This special issue focuses on how information and communication technology (ICT) can be leveraged to achieve sustainable consumption and sustainable supply chain management. One of the key objectives is to promote in-depth discussion on the technological, managerial, social, economic, and political implications of developing ICT capacity to support sustainability. In addition, we wish to generate insightful discussions on the connections between sustainable consumption and sustainable supply chain research. In the following section, we start by offering the readers of this special issue a short overview of these two research branches. 


\section{Sustainable consumption and sustainable supply chains}

Ethical consumption is a complex concept that can be understood from several points of view, including the subjects of ethical concern, such as fair labor or environment sustainability, organizational forms related to sustainability such as cooperatives or the motivations and incentives for consumers [2]. In general, research on consumption values extends Schwartz' theory of social values [24]. Information to consumers and the way it is distributed and used to make ethical purchasing decisions plays a key role in research on ethical consumption [3, 4, 21, 22]. In a sense, it can be argued that ethical consumption relies on information available at the purchasing point and consumer knowledge to understand and interpret this information [2]. The basic assumption is of course that consumers are rational actors seeking for products to satisfy their needs, optimally considering all available choices and information [9]. Consumer behavior is determined by ethical values and economic motives $[2,6]$. Main ethical values include, but are not limited to fair labor [15], human rights [14] or the environment [6]. Although there is an open debate in the literature on consumer motivations to consume ethically, with some researchers considering consumers as selfinterested [19], and others as altruistic actors [20], all researchers recognize an attitude-behavior gap. That is to say, research has found that although $30 \%$ of consumers state an intention to buy ethically, only $3 \%$ make the actual purchases accordingly [5]. Nonetheless, this intention is still the best predictor of behavior [1,20]. Intention is in turn mainly determined by information contained in the product's label [8]. Given the importance of price in the buying decision, alternative approaches to ethical consumption suggest to build into price all costs, including environmental and social costs of the products [7]. Finally, any purchasing decision is also heavily based on trust to both the information and the organization that produces the product $[16,26]$.

Given the importance of information and trust in driving ethical consumptions, it is not a surprise that several stakeholders in the supply chain, consumers and governments are promoting strategies to make information available, such as toxic release inventories, awards, ratings and certifications [19]. Private regulations such as the disclosure of corporate social responsibility (CSR) practices are also valuable tools with the potential of providing better information to consumers [7]. In all this practices, private companies play a key role as stewards of information and sustainable development [18], as well as government and nonprofits [27, 28].

Although the initial focus on improving organizational practices was on improving internal operations, it soon became obvious that a coordinated effort across all the supply chain was needed [12]. In this way, private companies looked for a more holistic approach from production, consumption, customer service to post-consumption of products [12, 18, 27]. Given the nature of today's economy, supply chain sustainability constitutes a global issue [12]. Again, sharing information across the supply chain becomes necessary for this approach to succeed [27]. Although there are many advances in building information-driven supply chains, we are still in the initial stages [25]. There are many incentives to manipulate access to information and there are too many open questions about how sharing information will impact the distribution of benefits and power in supply chains $[13,23]$. In this way, beyond the technical difficulties, sustainable supply chains will face important interorganizational and governance issues [10, 11, 17].

As we will describe in the following section, the set of papers in this special issue relate to different aspects of both themes. The 5 papers that we present in this issue are the result of a double blind peer review process that involved 19 manuscripts focusing on a wide variety of topics from researchers across the globe. They constitute a mix of theoretical and empirical efforts connecting supply chain information management for sustainability and consumer choice.

\section{Papers in the special issue}

The first paper in this special issue, "Challenges and Requirements for Developing Data Architecture Supporting Integration of Sustainable Supply Chains", Djoko Sayoko and his colleagues recognized that the lack of information about the social and environmental impacts of the products often create difficulties for individual consumer to assess and understand the implications of their choices in marketplace, which in aggregation, constraints the expansion of sustainable consumption. However, this information exists and is embedded in the supply chain in a fragmented and disparate form. The key to address the information asymmetry problem, thus, is to create capacity to integrate information and make it accessible to supply chain actors as well as end-consumers. Using the analysis of data collected through a series of interviews with key stakeholders in coffee supply chain, this paper identifies main challenges and requirements for such development. Some of the challenges that highlighted include data quality issue, limited technological capabilities, complex data ownership and disclosure policy, as well as unclear legal requirements. Based on the analysis of these challenges, the authors further made recommendations in developing and adopting technical and governance measures to deal with the challenges. 
Many organizations has espoused the CSR reporting practice, and disclose their environmental, social and governance performance information to stakeholders. It generate vase amount of data that can be the inputs to sustainable consumption and socially responsible investing (SRI). Understanding the role of Information technology in the development and use of the reports is important for designing and developing enabling platforms. The second paper in this special issue, "Corporate Social Responsibility Reporting Platforms: Enabling Transparency for Accountability," presented an information processing model of CSR reporting. Stephanie Watts's work was motivated by the perceived lack of theoretical clarity on the nature of sustainability reporting in the CSR reporting literature. She developed propositions associated with the reporting organization transparency, the reports transparency, and the users' perception as well as their adoption. Further, this research revealed that the design of the existing reporting platform is effective in serving the needs of SRI, but not sufficient to support sustainable consumption, and provided options for improve information provisions.

Increasing, the focus of addressing environmental performance has moved from a specific facility or organization to the entire supply chain. Green procurement, for example, has become an important approach towards broadening the adoption of environmental goals along supply chain. The paper by Ping Shi and colleagues, "A decision support system to select suppliers for a sustainable supply chain based on a systematic DEA approach", developed a decision support system for green supplier evaluation and selection. Using $\mathrm{C} 2 \mathrm{R}$ model of data envelopment analysis (DEA) and the super-efficiency DEA model, this work developed a reliable rating system for supplier evaluation based on environmental performance. Finally, the results from a case confirm the feasibility and applicability of this approach. Supplier selection represents a complex and difficult decision task. The DEA approach developed by this study enrich the theoretical discussion and practical applications for addressing environmental performance in green procurement.

The next paper took on again a different angle, and focuses on reverse logistics operations of the supply chain and the design of information technology to support such operations in order to minimize the negative health and environmental impact of hazardous waste and inappropriately disposed end-of-life (EOL) products. In this paper entitled, "RFID-based IT Infrastructure for Reverse Logistics Operations of End-of-life Pharmaceutical Products", Elif Kongar and her colleagues proposed a reverse logistics framework to take back, reuse, recycle, and disposal of EOL products. The proposed system would keep track of and provide real-time visibility of EOL pharmaceutical products throughout the reverse logistics operation. Therefore, it has the benefit of improve communication as well as overall performance of the reserve logistics operations. The authors further highlight the various environmental, economical, legal and physical goals and constraints in the consideration of deign.

The last paper of this special issue, "Sustainable development of the fresh agricultural products supply chain through the application of RFID technology" by Bo Yan and colleagues, investigated the application of RFID in fresh agricultural product supply chain to support sustainable development. Using an optimization approach and two cases of Fresh Agricultural Products' supply chains in China, they demonstrated that using RFID technology effectively reduces costs and increases profitability of different supply chain configurations. Their model reveals, however, that the cost of technology -in this case RFID tags-constitutes a key factor in the adoption process. Moreover, governance issues related to contracts and revenue-sharing play an important role in promoting cooperation inside the supply chain.

Acknowledgments The Guest Editors would like to thank the EICs for giving the opportunity and support to produce this Special issue. Further we would like to thank all the knowledgeable reviewers who gave their time and effort in bringing out a quality and timely special issue. The Guest Editors involvement in this special issue is partially supported by the US National Science Foundation under Grant Nos. 37656 and IIS-0540069, and the Consejo Nacional de Ciencia y Tecnología in Mexico under Grants No. 84082, 133670 and 171118. Any opinions expressed in this material are those of the authors and do not necessarily reflect the views of NSF, COMEXUS or CONACYT.

\section{References}

1. Ajzen I (1991) The theory of planned behavior. Organ Behav Human Decis Process 50(2):179-211

2. Barnett $\mathrm{C}$ et al (2005) Consuming ethics: articulating the subjects and spaces of ethical consumption. Antipode 37(1):23-45

3. Becker-Olsen KL et al (2006) The impact of perceived corporate social responsibility on consumer behavior. J Bus Res 59(1): $46-53$

4. Cailleba P, Casteran H (2010) Do ethical values work? A quantitative study of the impact of fair trade coffee on consumer behavior. J Bus Ethics 97(4):613-624

5. Carrington $\mathrm{M}$ et al (2010) Why ethical consumers don't walk their talk: towards a framework for understanding the gap between the ethical purchase intentions and actual buying behaviour of ethically minded consumers. J Bus Ethics 97(1):139-158

6. Choi S, Ng A (2011) Environmental and economic dimensions of sustainability and price effects on consumer responses. J Bus Ethics 104(2):269-282

7. Chouinard Y et al (2011) The sustainable economy. Harv Bus Rev 89(10):52-62

8. De Magistris T, Gracia A (2011) Do consumers pay attention to the organic label when shopping organic food in Italy? In: Reed $M$ (ed) Organic food and agriculture-new trends and developments in the social sciences. Janeza Trdine 
9. Freestone OM, McGoldrick PJ (2007) Ethical positioning and political marketing: the ethical awareness and concerns of UK voters. J Mark Manag 23(7-8):651-673

10. Gereffi $\mathrm{G}$ et al (2005) The governance of global value chains. Rev Int Polit Econ 1:78

11. Han K et al (2011) Information technology spillover and productivity: the role of information technology intensity and competition. J Manag Inf Syst 28(1):115-145 Summer 2011

12. Hsu C-C et al (2013) Supply chain drivers that foster the development of green initiatives in an emerging economy. Int J Oper Prod Manag 33(6):656-688

13. Johnston HR, Vitale MA (1988) Creating competitive advantage with interorganizational information systems. MIS Q 12(2):153-165

14. Lindenmeier $\mathbf{J}$ et al (2012) Consumer outrage: Emotional reactions to unethical corporate behavior. J Bus Res 65(9):1364-1373

15. Luchs MG et al (2010) The sustainability liability: potential negative effects of ethicality on product preference. J Mark 74(5):18-31

16. Luna-Reyes LF et al (2013) Information strategies to support full information product pricing: the role of trust. Inf Polity: Int J Gov Democr Inf Age

17. Luna-Reyes LF et al (2014) Full information product pricing: an information strategy for harnessing consumer choice to create a more sustainable world. Commun AIS 34(1):637-654

18. Matos S, Hall J (2007) Integrating sustainable development in the supply chain: the case of life cycle assessment in oil and gas and agricultural biotechnology. J Oper Manag 25(6):1083-1102

19. McEachern MG, McClean P (2002) Organic purchasing motivations and attitudes: are they ethical? Int J Consum Stud 26(2):85-92
20. Michaelidou N, Hassan LM (2010) Modeling the factors affecting rural consumers' purchase of organic and free-range produce: a case study of consumers' from the Island of Arran in Scotland, UK. Food Policy 35(2):130-139

21. Mohr LA, Webb DJ (2005) The effects of corporate social responsibility and price on consumer responses. J Consum Aff 39(1):121-147

22. Paavola J (2001) Towards sustainable consumption: economics and ethical concerns for the environment in consumer choices. Rev Soc Econ 59(2):227-248

23. Ponte S, Gibbon P (2005) Quality standards, conventions and the governance of global value chains. Econ Soc 34(1):1-31

24. Schwartz SH, Bilsky W (1987) Toward a universal psychological structure of human values. J Personal Soc Psychol 53(3):550

25. Steinfield C et al (2011) Through a glass clearly: standards, architecture, and process transparency in global supply chains. J Manag Inf Syst 28(2):75-108 Fall 2011

26. Swaen V, Chumpitaz CR (2008) Impact of corporate social responsibility on consumer trust. Rech Appl Mark (English Edition) 23(4):7-33

27. Vachon S, Klassen R (2007) Supply chain management and environmental technologies: the role of integration. Int J Prod Res 45(2):401-423

28. Zhu Q, Sarkis J (2004) Relationships between operational practices and performance among early adopters of green supply chain management practices in Chinese manufacturing enterprises. J Oper Manag 22(3):265-289 